\title{
A biomimetic approach to some specifically functionalized cyclic terpenoids ${ }^{\star}$
}

\author{
Veaceslav Kulciţki \\ Institutul de Chimie al AŞM, Chişinău, Republica Moldova
}

Received: 23 August, 2007; revised: 23 November, 2007; accepted: 03 December, 2007

available on-line: 12 December, 2007

\begin{abstract}
The paper relates on the current advancements in the synthesis of complex cyclic terpenoids by superacidic induced cyclization of open chain precursors. It is shown that functional groups disposal in the initial substrate strongly influences the reaction outcome. Possible variations of the investigated compound structures include particularly $\alpha$-functionalization and $\alpha, \omega$-bifunctionalization. This approach allowed a selective initiation of cyclization sequence from an internal double bond or suspending the ring closure cascade to partially cyclized compounds. The reported synthetic schemes are attempts to mimic the biogenetical processes postulated in the living systems.
\end{abstract}

Keywords: isoprenoids, cyclization, superacids

\section{INTRODUCTION}

Terpenoids are natural products widely spread in Nature. This is a very large group of compounds, perhaps the largest of all natural products. They can be found practically in any natural source: in humans and animals, in terrestrial plants, marine organisms and even in fossil sediments. Sometimes terpenoids are found in living systems connected to other compounds of different chemical nature, like proteins, quinones, heterocyclic compounds, playing a major role in the critical metabolic steps of living beings.

From the chemical structure point of view, terpenoids derive from only a single precursor, the C-5 isoprene unit. But the huge structural diversity of terpenoids is due to the infinite number of combinations that are possible on the condensation of isoprene units and following transformation of the obtained oligomers. These transformations include basically two distinct kinds of biochemical processes: cyclization reactions and functionalizations with dif- ferent heteroatoms. These transformations are catalyzed in vivo by enzymes and it is believed that they occur with a high degree of selectivity.

Different biogenetical schemes have been suggested to correlate the structure of complex terpenoids with their assumed precursors. The basis of all these schemes was the famous biogenetic isoprene rule formulated by Ruzicka during the middle of the last century. The methods of organic chemistry turned out to be reliable tools to prove all biogenetical correlations and to provide efficient procedures of access to valuable terpenoids in a biomimetic manner. These investigations contributed to the elucidation of a number of biogenetic processes mechanisms, confirmed by efficient biomimetical synthesis, which are as a rule the most efficient, short and economical.

The diversity of cyclic terpenoids is really tremendous. Synthetic organic chemists strive in their efforts to gain access to the known plethora of polycyclic backbones mostly by straightforward approaches, involving sequential building of the

\footnotetext{
${ }^{\star}$ This paper is dedicated to Professor Tadeusz Chojnacki from the Institute of Biochemistry and Biophysics, Polish Academy of Sciences in Warsaw on the occasion of the 50th anniversary of his scientific activity and 75th birthday.

${ }^{\bowtie}$ Corresponding author: Veaceslav Kulcițki, Institutul de Chimie al AŞM, str. Academiei, 3, MD-2028, Chişinău, Republica Moldova; tel.: (373) 22739 769; fax: (373 22) 739 954; e-mail: kulcitki@yahoo.com

Abbreviations: Ac, acetyl; Bn, benzyl; DHP, dihydropyrane; Et, ethyl; Me, methyl; NBS, N-bromosuccinimide; Ph, phenyl; PPTS, pyridinium para-toluenesulfonate; Py, pyridine; THF, tetrahydrofurane; THP, tetrahydropyranyl; r.t., room temperature.
} 
complex molecules from the synthons prepared by classical organic chemistry transformations. These approaches have biomimetic character only in very few separate examples, since mechanistically, classical organic transformations are far away from the biogenetical processes. Although nowadays new enzymes are being discovered to catalyze such classical chemical reactions like Baeyer-Williger oxidation or Diels-Alder cycloadition, biosynthesis of cyclic terpenoids is based on rather simple cyclization (isomerization)-oxidation (functionalization) sequences having either acid-base or free radical catalysis. We will bring herein examples of successful biomimetic approaches towards complex cyclic terpenoids using superacids as cyclization promoters.

\section{SYNTHESIS OF CYCLIC TERPENOIDS BY ENZYMATIC AND CHEMICAL CATALYSIS. SIMILARITIES AND DIFFERENCES}

Planning and performing of a biomimetical chemical transformation is based on considering the hypothetical mechanism of enzyme catalysis, which is highly specific and efficient. The source for this specificity is attributed first of all to the ability of the enzyme to stabilize the conformational mobility of the terpenic chain. This feature is very important especially for the cyclization processes. These processes involve formation of several stereocenters from an achiral molecule. Consequently, the number of possible isomers of obtained cyclic products depends on the number of these centers. For example the achiral, aliphatic sesquiterpenoid $E, E$-farnesol (1) (3 isoprene units) is considered as biogenetical precursor of the bicyclic drimenol (2), which has 3 asymmetric carbon atoms and a double bond (Scheme 1). The total number of stereoisomers of drimenol equals $2^{3}$ and can be also multiplied if the possibility of double bond position variation is considered $\left(\Delta^{7,8} ; \Delta^{8,9} ; \Delta^{8,12}\right)$. Therefore, we can expect formation of 20 isomers on cyclization of the relatively simple farnesol.
But in real biological systems no such diversity of products is observed. The biochemical process in the living organism leads specifically to only one compound. For such a selectivity, conformational mobility should be reduced to a minimum by the enzyme or practically locked.

Another important feature of the enzyme is its ability to initiate efficiently the chemical process of cyclization or functionalization itself. For the abovementioned example of farnesol-drimenol it means that a protonation-deprotonation sequence has to be initiated specifically at the $\omega$-terminal double bond (tail) of farnesol and terminated by removal of the proton from C-7 position of resulting drimenol (Scheme 1). It is noteworthy that efficient termination of the cyclization sequence is also a very important aspect that contributes heavily to the overall process selectivity and efficiency.

Basing on these considerations, various organic transformations have been elaborated to mimic in vitro the enzymatic mechanisms of terpene biosynthesis (Torre \& Sierra, 2004). We will relate below on the use of superacids as efficient promoters of selective biomimetic cyclizations of specifically functionalized terpenoids.

The history of using superacids as terpene cyclization promoters goes back to the 1970's. Soviet chemists M. Kurbanov, A. Semenovskii and V. Smit related for the first time on the use of fluorosulfonic acid as a cyclization agent more efficient than conventional protonic acids (Kurbanov et al., 1973). The choice of a superacid was reasonable, since it allowed performing the synthetic procedure in very mild conditions. The very active fluorosulfonic acid could initiate cyclization of a terpenic substrate at a temperature as low as $-78^{\circ} \mathrm{C}$ or even lower. It is known that at these temperatures the conformational mobility of the flexible terpenic chain is dramatically diminished. Therefore, the reaction conditions resemble the enzymatic catalysis in an attempt to favour a conformation that is more likely to deliver selectively only one cyclic product. Under these circumstances, the superacid selectively initiate a

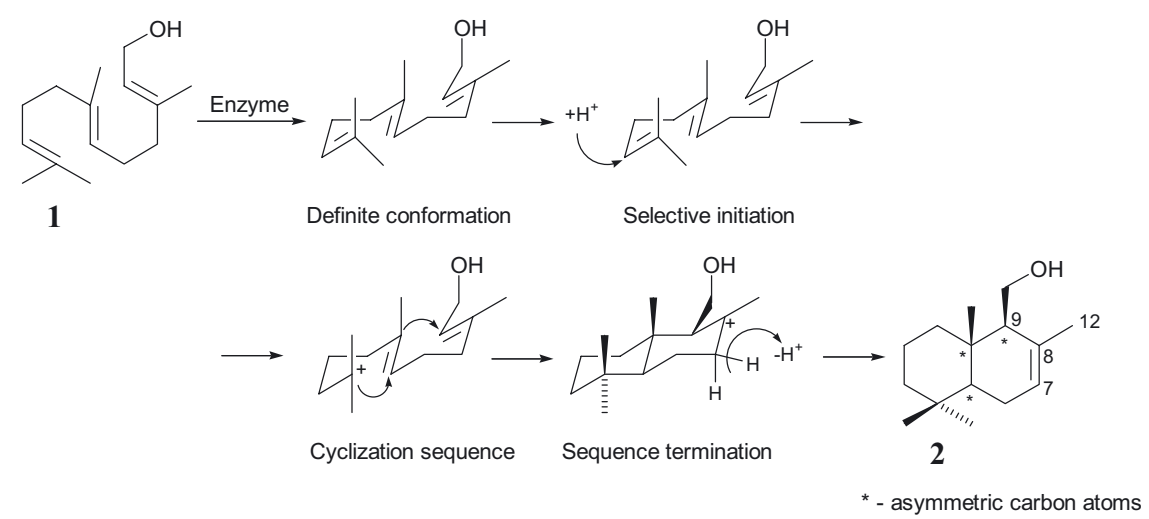

Scheme 1. A hypothetical biogenetical scheme for drimenol in vivo synthesis 
cyclization sequence according to a mechanism that is also valid for enzymatic catalysis. In our opinion this feature is one of the crucial aspects of the biomimetic nature of superacid-catalyzed cyclizations.

The other advantage of the superacid that is also very important for the process efficiency and selectivity is given by its extraordinary ability to initiate the protonation sequence and to assure a sufficiently long life of the formed carbonium ions. And this property of the superacid is due to the corresponding counter-ion that in fact determines the superacidic properties of the superacid (protons are the same for all acids). Under these circumstances, the formed carbonium species are sufficiently stable to achieve an equilibrium where the more stable conformation prevails. The factor of space that is valid for enzymatic catalysis is substituted in this case by the factor of time, supported by an acid that is able to keep the "status quo" of the intermediate carbonium species.

And finally, the selectivity of the termination step is provided by the stereochemical circumstances that appear in the cyclic compounds and the added base (usually an amine or even aqueous inorganic bases) removes the protons selectively from a certain position to provide the target cyclic compound.

It is obviously understood that enzymatic cyclizations are still unrivalled in selectivity by traditional chemical transformations. But nevertheless, we are permanently challenged by the complexity and beauty of the natural terpenoids to continue our endeavours in developing new chemical processes that resemble Mother Nature in her fascinating opera of Creation. The discussion below will provide an account of the successful approaches employed for the synthesis of some complex cyclic terpenic compounds starting from available substrates and basing on the biomimetic philosophy.

\section{CYCLIC TERPENOIDS. CHALLENGES OF THE NATURE}

The chosen target cyclic terpenoids include fully condensed cyclic systems, cyclic systems having a free $\alpha$-prenyl group and cyclic systems having a free $\omega$-prenyl group.

Compounds of such structures are widely found in natural sources and most often show interesting biological activity.

Examples of terpenoids with fully condensed structures spread from monoterpenes to triterpenes and higher polycyclic isoprenoids found in fossil sediments. Their biological activity is mostly connected with additional oxygen-functionalization. Prominent examples are sesquiterpenic compounds of drimanic structure like polygodial 3, warburganal 4, and albicanol 5 .

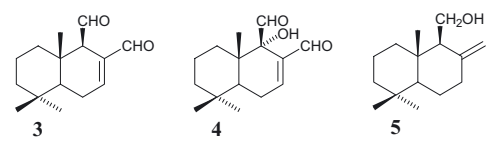

Drimanes occur both in plants and in marine organisms and play an essential role from the chemical ecology point of view, being part of the host defensive system. These compounds show antibacterial, antifungal, antifeedant, plant-growth regulatory, cytotoxic, phytotoxic, piscicidal and molluscicidal effects. An excellent review on drimane chemistry has been published recently (Jansen \& de Groot, 2004). Some very recent reports on drimane synthesis and biological activity are also available (Malheiros et al., 2005; Della Monica et al., 2007).
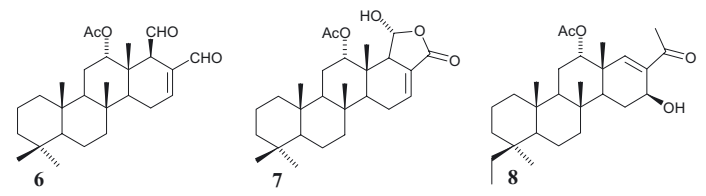

Other examples of biologically active fully condensed cyclic compounds are sesterterpenic scalaranes, basically found in marine organisms. Scalaranic compounds like scalaradial 6 and scalarin 7 play important ecological roles and possess interesting biological properties as well. For example the dialdehyde 6, which was isolated from the marine sponge Cacospongia mollior, displayed fish antifeedant properties and strong cytotoxicity (Cimino et al., 1974; 1987). It has also been shown that compound 6 strongly inhibits the hydrolytic activity of the enzyme, phospholipase A2 (PLA2) (De Carvalho \& Jacobs, 1991; Potts et al., 1992). And marine sponges continue to provide biologically active scalaranes, a recent example being compound 8 , which showed cytotoxicity at low concentrations (Lan \& Li, 2007).

Another group of presented compounds has a free prenyl group attached to the "head" site of the cyclic backbone, namely at the $\alpha$-terminus. This kind of compounds are widely distributed in various natural sources. For example the diterpenic cheilanthanes cheilanthatriol 9 and cheilanthadiol $\mathbf{1 0}$ have been isolated from ferns. Spongianolides A 11 and B 12 have been isolated from marine sponges, which proved to be a source of various cheilanthanes.
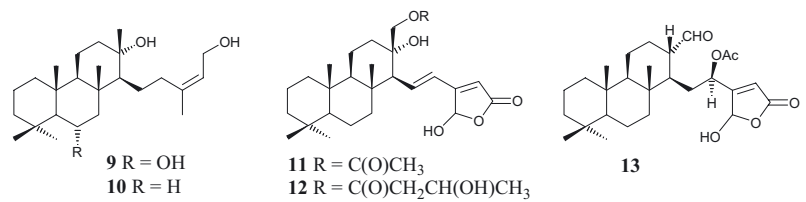

Cheilanthanes, especially highly oxygenated ones, showed diverse biological activity. Luffolide 13 possess anti-inflammatory activity and inhibits 
the hydrolysis of phosphatidylcholine by bee venom PLA2 (Kernan et al., 1989), compounds $\mathbf{1 1}$ and 12 potently inhibited $\left(\mathrm{IC}_{50}=0.50-1.40 \mu \mathrm{g} / \mathrm{mL}\right)$ proliferation of the mamary tumor cell line MCF-7 (He et al., 1994).

And the last group of specifically functionalized cyclic terpenoids has a functionalization given by the free $\omega$-prenyl group attached to the cyclic system. This kind of structure is represented in natural sources by compounds of sacculatanic family, broadly found in liverworts (Asakawa, 2001; 2004). The continuous search for new sacculatanes is due to the biological activity shown by the representative members of this compound class, including piscicidal, antimicrobial, anti-HIV and cytotoxic activities. Further investigations of the biological activity of other sacculatanes are hampered by the limited availability of these compounds from natural sources. As a solution of this problem, interesting examples of growing liverworts in axenic culture have been reported recently (Feld et al., 2005). On the other hand, chemical synthesis of sacculatanes could also provide sufficient quantities for biological activity and SAR studies. Selected representatives of sacculatanes include sacculatal 14, perrottetianal 15 and the cycle A oxygenated sacculatane $\mathbf{1 6}$.
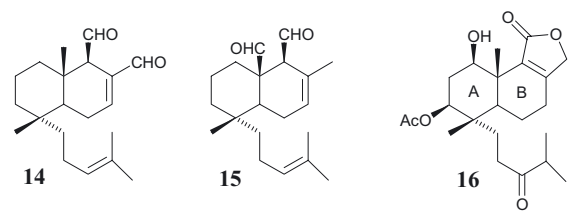

\section{SUPERACIDIC CYCLIZATION OF TERPENIC MONOFUNCTIONAL SUBSTRATES. SYNTHESIS OF CONDENSED POLYCYCLIC SYSTEMS}

Most of the open chain terpenic substrates have only one functional group at the $\alpha$-terminus (head). These compounds are readily available and, what is more important, they represent excellent models for performance of biomimetic cyclizations.

The first terpenic substrate that was submitted to superacidic cyclization was the well known geraniol (17). Treatment of this compound with fluorosulfonic acid in nitropropane for $5 \mathrm{~min}$ provided $\alpha$-cyclogeraniol (18) with an acceptable $62 \%$ yield (Kurbanov et al., 1973). Latter on, a whole range of terpenic substrates have been investigated in superacid-promoted cyclizations. These investigations were reflected in numerous review papers and publications (Bartlett, 1984; Sutherland, 1991; Vlad, 1993; Jaquesy, 1997; Kulcițki et al., 1998; Brunoldi et al., 2006). It appeared that the outcome of cyclization is not strongly dependent on the chain length of the investigated substrate.

Most of the examples reported in the literature showed that in the series: monoterpenic-sesquiterpenic-diterpenic-sesterterpenic substrates cyclization processes lead to completely cyclized products with the trans-stereochemistry between cycles. This is shown by examples of the homologous series of $\alpha-E$ alcohols 17 (monoterpene, C-10), 1 (sesquiterpene, C-15), 19 (diterpene, C-20) and 21 (sesterterpene, C-25) (Scheme 2). Slight differences were seen only in the cyclic product yield, which appeared to be highest for the C20-C15 substrates 19 and $\mathbf{1}$ (87\% and $75 \%$, respectively).

Two other structural features are critical for the structure of the cyclic products formed. First of all it is the nature of the functional group at the $\alpha$-terminus of the chain. The range of investigated functional groups was quite large: alcohols, their acetates, acids and their esters, phenylsulfones, as well as aldehydes and ketones. General schemes of cyclizations for the representative examples of these substrates are presented in Scheme 3.

In the case of regular structure substrates of general formula I, cyclization proceeds with formation of completely cyclic compounds II, containing an olefinic double bond in the last cycle. The reaction course in this case is similar to the enzymatic mechanism discussed in Scheme 1.

The situation is different in the case of the presence in the substrate molecule of a functional group that is capable of stabilizing the cyclic carbonium ions via a 5- or 6-membered transition state. In this case the reaction products have different structures: for the acetate of general formula III, the reaction product is a hydroxyacetate of general formula IV. Homoalcohols V provide the cyclic oxides VI, homo-acids VII and bishomo-acids IX provide the corresponding $\gamma$ - and $\delta$-lactones VIII and $\mathbf{X}$, respectively, while ketones XI lead to the cyclic enolethers XII. All these substrates have a nucleophile at the

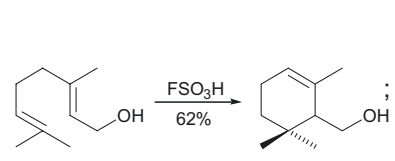

17

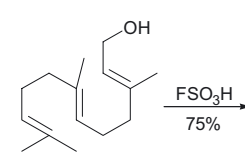

1

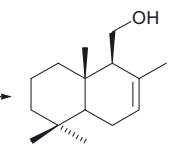

2

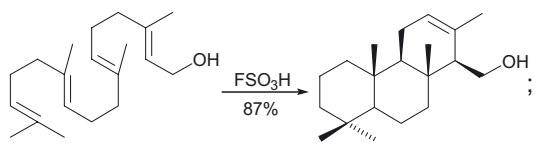

19

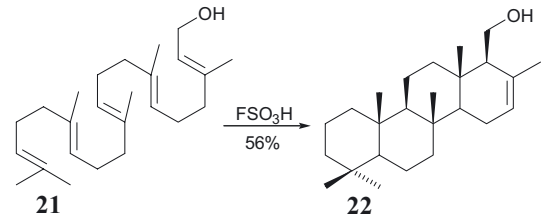

Scheme 2. Superacidic cyclization of $\alpha-E$ terpenic alcohols. 


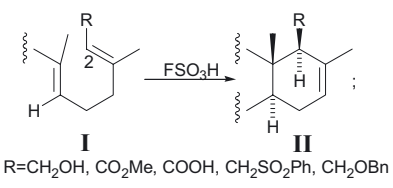

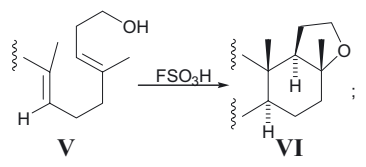

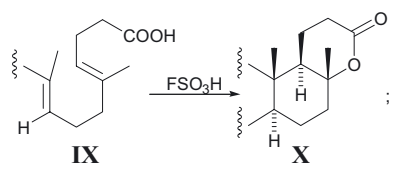

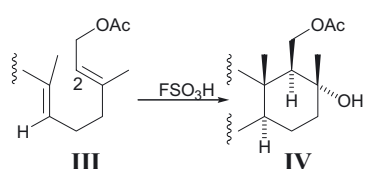
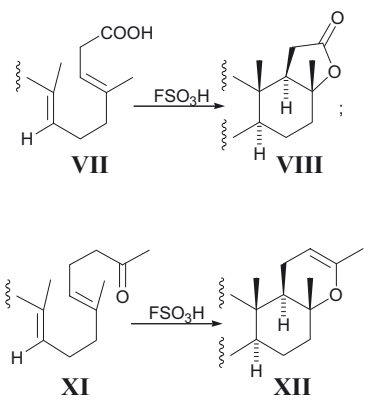

Scheme 3. Superacidic cyclization of terpenic substrates with different $\alpha-E$ functional groups. $\alpha$-terminus of the molecule that can play the role of efficient terminators of cyclization sequence to provide either the product of last cycle double bond hydration (hydroxyacetate IV), or the product with an extra cycle (oxide, lactone or enolether), depending on the functional group character. In fact, the functional group at the $\alpha$-terminus catches efficiently the cyclic carbonium ions, leading to the corresponding additional cycle closure. The general mechanism of this internal quenching sequence is depicted in Scheme 4 .
It is noteworthy that the yields of cyclization products in these cases are higher and this proves the hypothesis that an efficient termination of the cyclization sequence plays also an essential role for a selective and high yielding process.

The second factor that also influences strongly the stereochemical outcome of the cyclization cascade is the configuration of the double bond at the $\alpha$-terminus. The cyclization substrates shown in Schemes 2-4 have the 2E-configuration. Basing on the hypothesis that the ring closure takes place

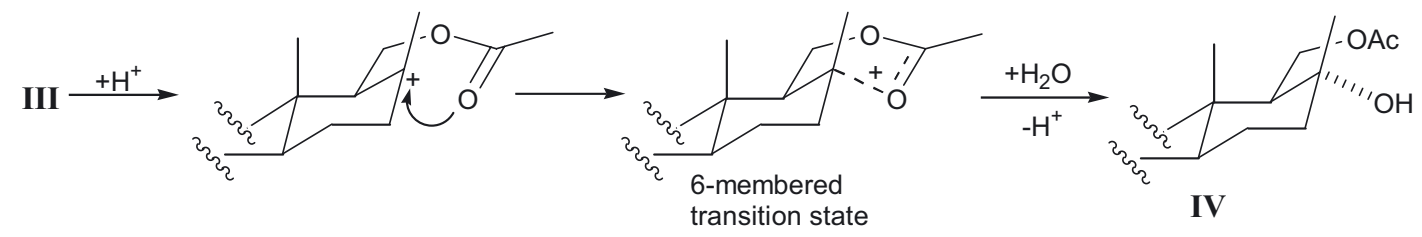

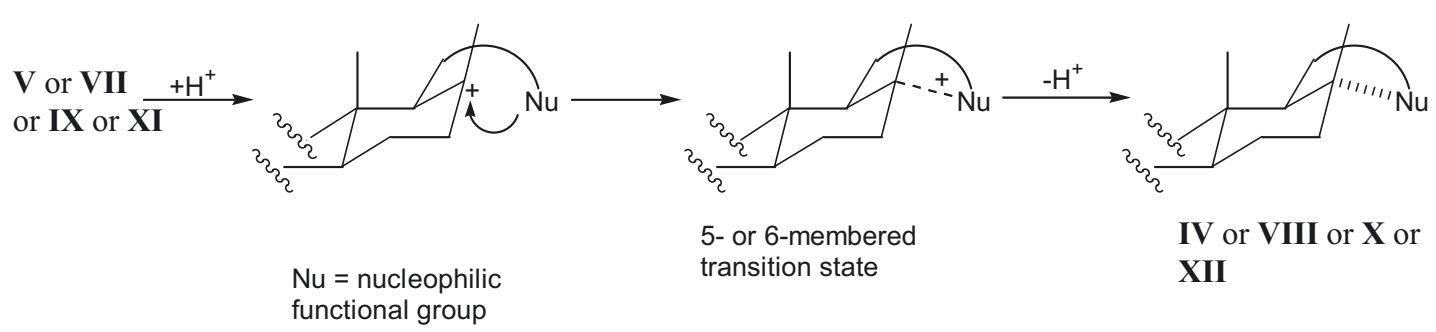

Scheme 4. The mechanism of carbonium ion trapping by an internal nucleophile after the cyclization sequence.
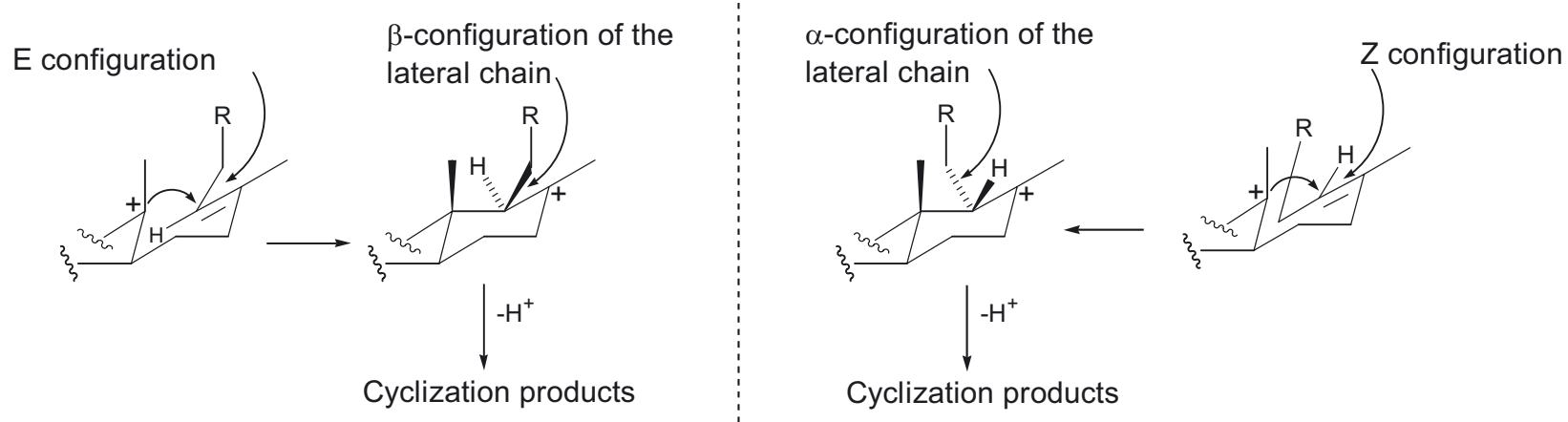

Scheme 5. The stereochemical mechanism of ring closure for $2 E$ - and 2Z-terpenic substrates. 

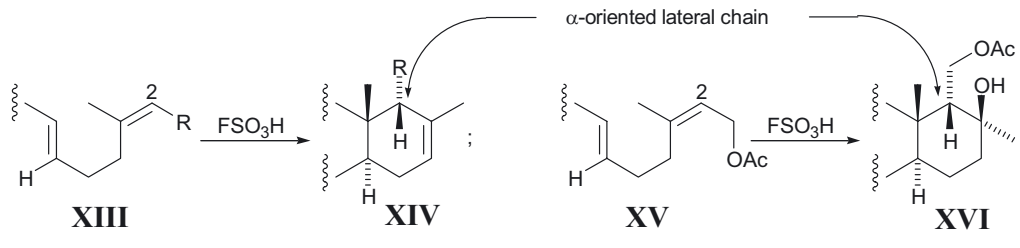

$\mathrm{R}=\mathrm{CH}_{2} \mathrm{OH}, \mathrm{CO}_{2} \mathrm{Me}, \mathrm{COOH}, \mathrm{CH}_{2} \mathrm{SO}_{2} \mathrm{Ph}, \mathrm{CH}_{2} \mathrm{OBn}$

from the less hindered $\alpha$-face of the cyclic molecule (Scheme 5), the lateral chains in either final cyclic compounds or 5/6-membered transition states have a $\beta$-orientation.

Consequently, cyclization of substrates with 2Z-configuration of the double bond shall lead to cyclic compounds with $\alpha$-oriented lateral chain. A general reaction scheme for these situations is shown in Scheme 6.

We have also to mention that the cyclization reaction is completely stereospecific in this case, no other lateral chain epimers have been detected for all investigated substrates.

\section{SUPERACIDIC CYCLIZATION OF POLYPRENOL- LIKE SUBSTRATES. SYNTHESIS OF CYCLIC SYSTEMS HAVING A FREE $\alpha$-PRENYL GROUP}

Polyprenols represent a large class of natural linear isoprenoids that occur abundantly in the plant kingdom. Their diversity is due to the chain length (up to thousands isoprenoid units as in natural rubber) and the configuration of the double bonds (Swiezewska et al., 1994). Biomimetic-like cyclization of long-chain polyprenols has also been investigated and successful attempts of both enzymatic (Renoux \& Rhomer, 1986) and superacidic (Schaeffer et al., 1994; Grosjean et al., 2001) cyclization of all-trans substrates have been reported. On the other hand, it is known that most of the natural long-chain polyprenols possess the di-trans-poly-cis-configuration. That was the reason to start an investigation of the influence of the internal Z-configured double bonds that are present in polyprenols on the cyclization process of corresponding substrates. This investigation could have shed more light on the biogenetic relationship between long chain polyprenols found in plants and polycyclic compounds isolated from different natural sources, including fossil sediments.
It was also reasonable to expect a deeper elucidation of the cyclization process mechanism for the case of such complex substrates.

With this purpose, the simplest sesterterpenic polyprenol-like substrates $\mathbf{2 3}$ and $\mathbf{2 4}$ had been synthesized and submitted to superacid-induced cyclization (Grinco et al., 2007a). It was decided to investigate the superacidic cyclization of esters 23 and 24, instead of their corresponding alcohols due to the fact that long-chain terpenic alcohols tend to sediment at low temperatures, under standard conditions of superacidic cyclizations. Evolving of the biphasic system favours local temperature jumps so that elimination reaction prevails. Both the yield and the selectivity of the cyclization products are altered. Tentative changing of the cyclization procedure by switching to the addition of substrate to the solution of superacid did not improve the overall reaction performance.

Synthesis of sesterterpenic esters 23 and 24 was based on a sequential homologation of 2Z-geranylgeraniol 25 (Scheme 7). Its bromination with phosphorus tribromide provided the bromide 26, which was submitted to alkylation with sodium ethylacetoacetate. The obtained ketoester 27 was decarboxylated on refluxing with an ethanolic solution of potassium hydroxide. The resulting ketone 28 was olefinated with trimethylphosphonoacetate to provide a mixture of esters 23 and 24 . HPLC separation provided individual esters 23 and 24 .

Superacidic cyclization of the 2Z,6Z-ester 23 (Scheme 8) under the standard superacidic cyclization conditions led to a product mixture that was submitted to hydrolysis on treatment with an ethanolic solution of potassium hydroxide. This procedure was introduced for the selective hydrolysis of partially cyclized compounds and following separation from completely cyclic ones (unhydrolyzed) by flash chromatography. Separation provided the scalaranic ester $29(26 \%)$, along with a polar acid,

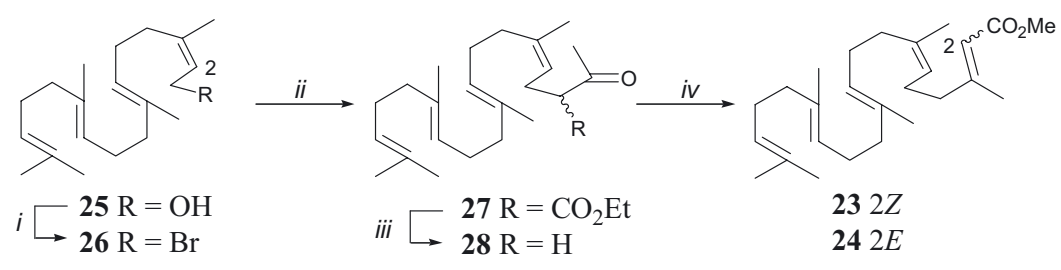

Scheme 7. Reagents and conditions.

(i) $\mathrm{PBr}_{3}, \mathrm{Py}, \mathrm{Et}_{2} \mathrm{O}, 0^{\circ} \mathrm{C}, 2 \mathrm{~h}$ and $12 \mathrm{~h}$ at r.t., 97\%; (ii) $\mathrm{MeC}(\mathrm{O}) \mathrm{CH}_{2} \mathrm{CO}_{2} \mathrm{Et}, \mathrm{Na}, \mathrm{PhMe}$, reflux, 2 h, 87\%; (iii) $10 \% \mathrm{KOH}$ in $\mathrm{EtOH}$, reflux, $2 \mathrm{~h}, 64 \%$; (iv) $(\mathrm{MeO})_{2} \mathrm{P}(\mathrm{O}) \mathrm{CH}_{2} \mathrm{CO}_{2} \mathrm{Me}$, MeONa, $\mathrm{C}_{6} \mathrm{H}_{6^{\prime}}$, reflux $3 \mathrm{~h}, 82 \%(23 / 24=\sim 1: 3)$. 


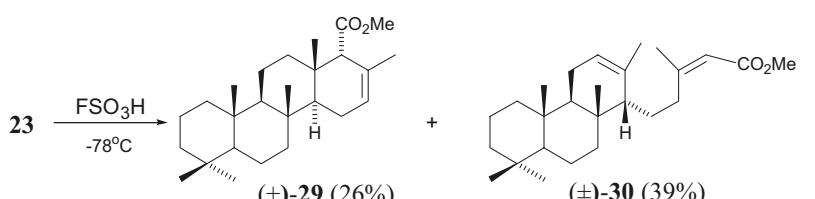

$( \pm)-29(26 \%)$

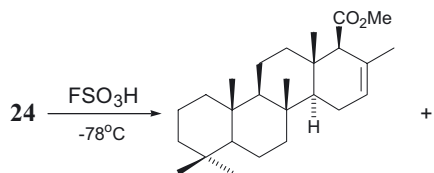

$( \pm)-\mathbf{3 1}(25 \%)$

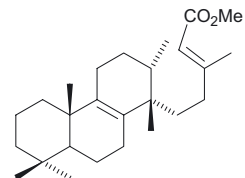

$( \pm)-32(63 \%)$

Scheme 8.

which was methylated with an ethereal solution of diazomethane to provide the cheilanthanic ester $\mathbf{3 0}$ (39\%).

The prevalence of the partially cyclized ester 30 in the reaction mixture was quite surprising and showed that the internal double bond in the initial substrate $\mathbf{2 3}$ contributes to the selective suspension of the cyclization cascade to form a tricyclic compound with a lateral chain of cheilanthanic structure. This effect was confirmed by the following studies. A similar cyclization of the 2E,6Z-ester 24 also provided selectively a partially cyclized product - the rearranged cheilanthane $32(63 \%)$, along with the known tetracyclic scalarane 31 (25\%). Formation of minor amounts of completely cyclized compounds 29 and 31 with trans-fusion of cycles is an additional proof that the cyclization process represents a stepwise sequence which includes successive protonation-deprotonation steps that lead to more stable compounds. This conclusion was confirmed a priori during our earlier investigations of bicyclic, optically active sesterterpenoids cyclization (Ungur et al., 2002). The investigated substrates were bicyclogeranylfarnesoic acid methyl esters 33 and 34, having similar configuration of the internal double bonds as the open chain substrates 23 and 24 . In fact, the bicyclic core of 33 and 34 can derive from an open chain precursor with $E, E$-configuration, the hypothetic precursor of these bicyclic esters could be open chain esters 23 and 24 possessing polyprenollike configuration of the double bonds.
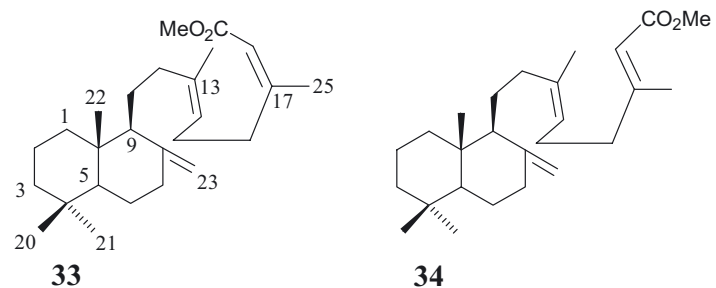

Cyclization of the bicyclic compounds 33 and 34 provided the same compounds 29,30 and 31,32 , with the same selectivity, but in an optically active form. The reaction mechanism was tentatively explained (Scheme 9).

The protonation of the ester 33 generates the carbocation 35 , which is then attacked by the $\Delta^{13(14)}$ -double bond from the $\alpha$-side of the molecule (less sterically hindered), forming the tricyclic intermediate carbonium ion 36. The proton at $\mathrm{C}-14$ has the $\beta$-orientation, due to the cis-configuration of the $\Delta{ }^{13(14)}$ double bond in 33. Although one can assume that carbonium ion $\mathbf{3 6}$ is stable at low temperatures in the superacidic media, nevertheless closing of D ring to give the $\mathrm{C} / \mathrm{D}$-cis fused scalarane 37 does not take place. Most likely this is due to the steric hindrance created by the cyclic backbone to the lateral chain. This has been revealed on simulated molecular models using an MM2 method. Minimisation of the steric energy for the ion $\mathbf{3 6}$ showed that the spatial arrangement of the lateral chain in this substrate, so that the distance between C-13 and C-18 is lower than $3 \AA$, is accompanied by a high steric repulsion energy.

The fact that the lateral chain in the hypothetical intermediate $\mathbf{3 6}$ can not be involved in the next cyclization step due to stereochemical reasons can be a very reasonable explanation of the selective suspending of cyclization sequence with the formation of the tricyclic cheilanthane 30. In fact, all sesterterpenic structures of this kind (scalaranes and cheilanthanes) have been isolated from plants and fossil sediments (Kamaya et al., 1996; Jaki et al., 2000; Ungur \& Kulcițki, 2007), and on the basis of these results we can assume that their possible biogenetic precursors could be polyprenols or polyprenol-like compounds which are also widespread plant metabolites.

The trans-isomeric ester $\mathbf{3 4}$ follows a similar mechanistic pathway via the tricyclic carbonium ion 42 to give a mixture of the rearranged cheilanthane 32, along with a minor amount of scalaranic ester 31. The only difference in this mechanism is the fact that the ion $\mathbf{4 2}$ suffers a hydride shift to produce the intermediate ion 46, followed by a C8-C14 methyl migration to provide the rearranged ion 47 and finally the resulting tricyclic ester $\mathbf{3 2}$.

\section{SUPERACIDIC CYCLIZATION OF $\alpha, \omega-$ BIFUNCTIONAL SUBSTRATES. SYNTHESIS OF CYCLIC SYSTEMS HAVING A FREE $\omega$-PRENYL GROUP}

\section{Monoterpenes}

The general biogenetic mechanism of terpene cyclization shown in Scheme 1 leads to cyclic compounds with an unfunctionalized A-ring. But numerous examples of natural cyclic terpenoids have a very well developed ring A functionalization. The hypothetical biogenetical precursors of these compounds 

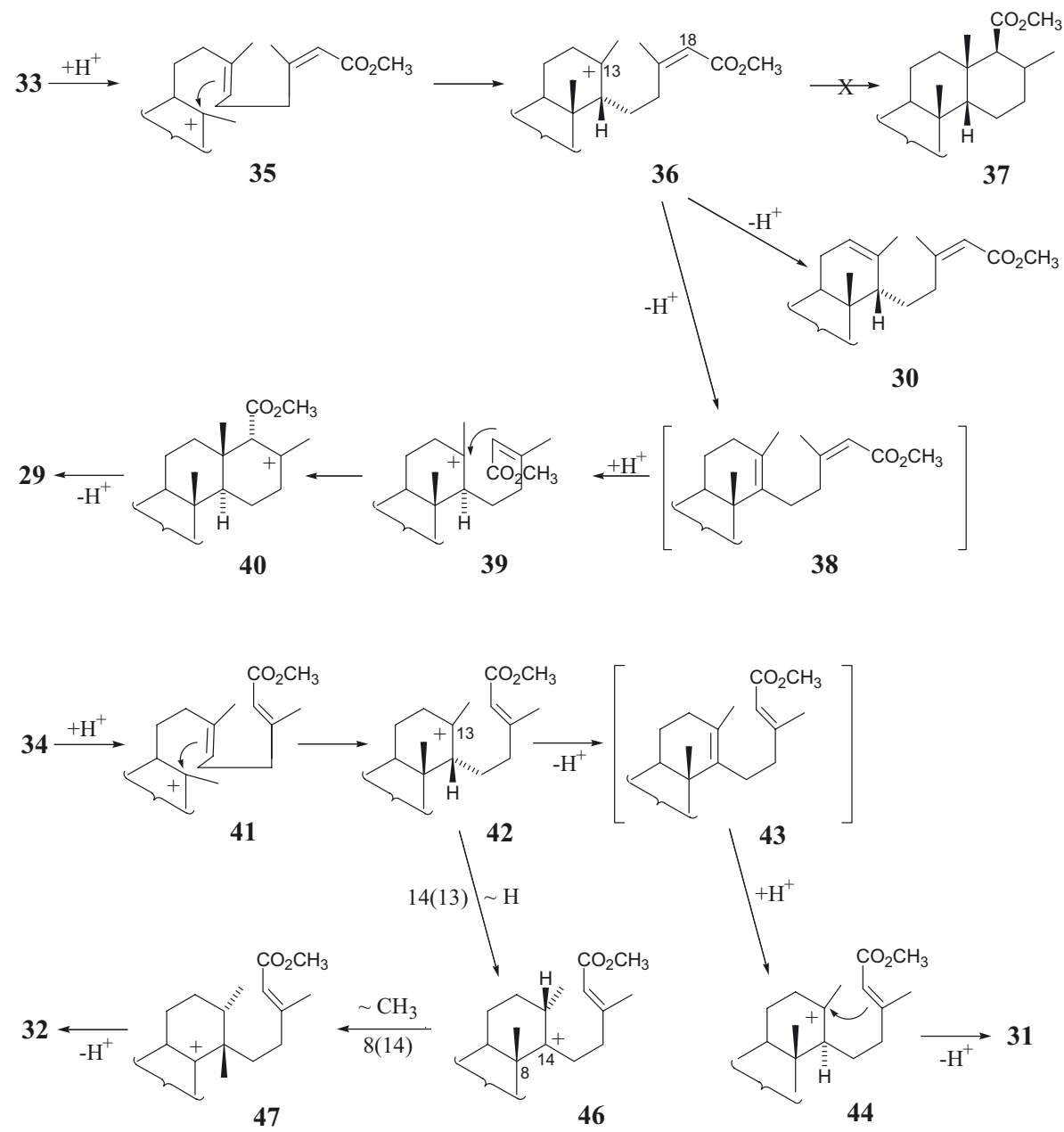

Scheme 9. Reaction mechanism suggested for cyclization of bicyclic esters 33 and 34 .

are the corresponding $\omega$-epoxides XVII that under enzymatic catalysis conditions can provide cyclic products with a hydroxyl group at C-3 position of the A-ring of general structure XVIII (Scheme 10).

Having promising results on biomimetic induced superacidic cyclization of monofunctional terpenoids it was logical to investigate superacid-induced cyclization of terminal epoxides in an attempt to mimic the corresponding biogenetical scheme. It was shown in the previous investigations of VanTamelen and collaborators that protonic and Lewis acids can be initiators of terminal terpenic epoxide cyclizations (Van Tamelen, 1968; Van Tamelen \& McCormic, 1969; Van Tamelen et al., 1982).

Basing on the idea that superacids are better promoters of biomimetical cyclizations of terpenoids, readily available terminal epoxides of geranylacetate

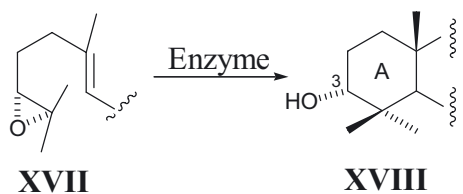

Scheme 10. Enzymatic cyclization mechanism of terminal terpenic epoxides.
48 and 49 were submitted to the standard procedure of superacidic cyclization (Scheme 11). But contrary to expectations, fluorosulfonic acid could not initiate a carbocyclization process by specific opening of the epoxide group (Korchagina et al., 1993; Ungur et al., 1993a; 1993b). Both substrates provided reaction products 50-54 related only to epoxy-group opening (Scheme 11).

The failure of cyclization process in the case of the terminal epoxides 48 and 49 has stimulated the search for other functional groups that could be attached to the $\omega$-terminus of the terpenic chain in order to provide highly functionalized cyclic compounds. Taking into consideration the specific affinity of the superacid for the double bonds, the diacetylated derivative of geraniol $\mathbf{5 5}$ was submitted also to superacidic conditions (Kulcițki et al., 1999). The reaction was quite sluggish in this case, and a fraction of the substrate 55 remained unreacted. The transformed product represented a mixture of polar diastereomeric compounds $\mathbf{5 6}$ and 57 (Scheme 12).

Their formation was explained by a mechanism completely different from that based on the initial protonation of the terminal double bond. In this 


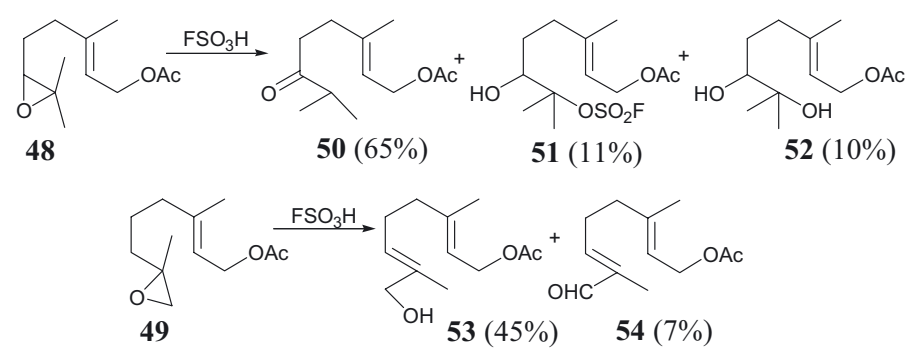

Scheme 11. Interaction of monoterpenic terminal epoxides with fluorosulfonic

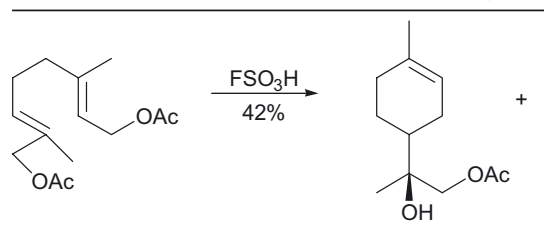

55

56

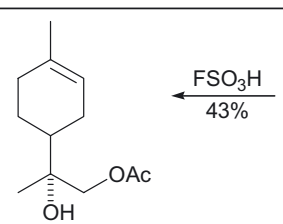

57

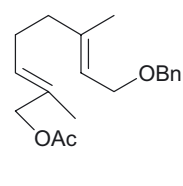

58
Scheme 12. Superacidic cyclization of $\alpha, \omega$-bifunctionalized monoterpenic substrates. case the superacid caused elimination of the functional group from the $\alpha$-terminus of the molecule, accompanied by cyclization according to a $p$-menthanic mechanism. This mechanism is viable in living systems and usually is initiated by elimination of the pyrophosphate group from the $\alpha$-terminus of the isoprenoid chain. To the best of our knowledge there is only one report when a non-pyrophosphate functional group is protonated by an acidic agent in vitro, followed by a cyclization initiated from the head-site of the molecule (Gavriliuk et al., 1988). The consistency of this mechanism was proved by further cyclization experiments with the monoterpenic bifunctionalized substrate $\mathbf{5 8}$, which bears a benzyl group at $\mathrm{C} 2$ and an acetate group at the $\omega$-end. Under the same superacidic treatment, substrate $\mathbf{5 8}$ provided the same reaction products 56 and 57. It was quite unexpected that the stable benzylic protection was removed under reaction conditions. This reaction course (Scheme 13) was explained by a special stereoelectronic effect of the $\omega$-acetate group which could be also protonated after the treatment with the superacid.

Under these circumstances following protonation of the terminal double bond is not possible, since it would bring about formation of an unstable 1,3-dicationic system. On the other hand, the protonation of the oxygenated functional group from the C2 position (acetate or benzyl) is followed by an allylic stabilization which favours cyclization according to the $p$-menthanic mechanism, followed be elimination of the functional group from $\mathrm{C} 2$. The cyclic carbonium ion 63 is stabilized by a 5 -membered transition state 64 , followed by hydration to provide a mixture of hydroxyacetates $\mathbf{5 6}$ and $\mathbf{5 7}$.

These transformations did not have too much of a synthetic value. On the other hand, this example was a simulation of blocking the $\omega$-terminus of the terpenic chain by an additionally disposed functional group. As a result the $\omega$-double bond was inhibited and could be hardly involved in a cyclization sequence. Therefore, the cyclization process could be initiated selectively from another position different from the terminal one. This strategy was employed in the following studies of the cyclization of sesqui- and diterpenic $\alpha, \omega$-bifunctional substrates.

\section{Higher terpenes}

The conclusion that the terminal functional group in the monoterpenic substrates efficiently "protects" the corresponding double bond from being involved in the cyclization sequence promoted the idea to perform a systematic study of the behaviour of sesqui- and diterpenic $\alpha, \omega$-bifunctional substrates in superacidic media. Both sesqui- and
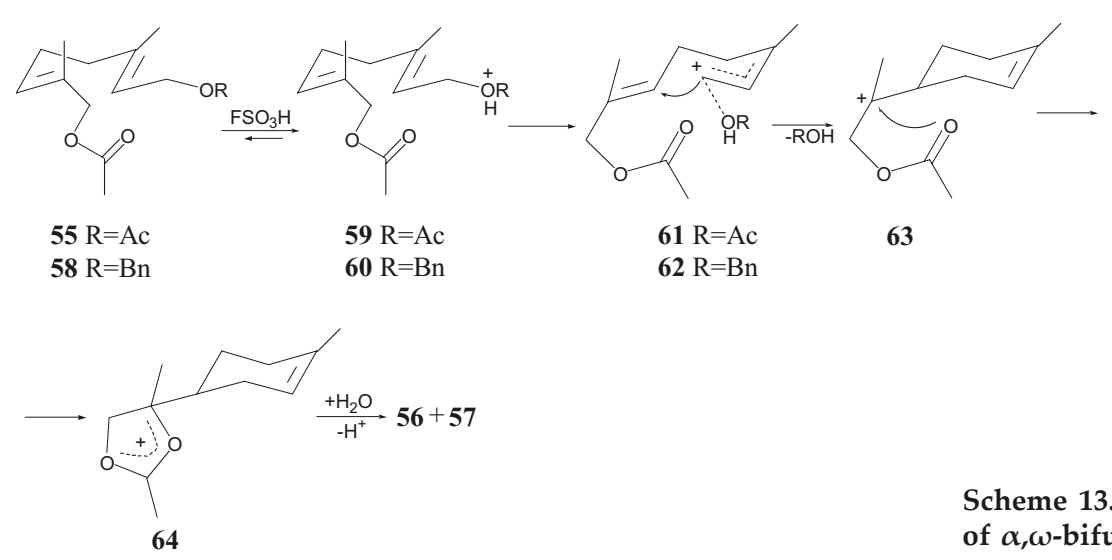

Scheme 13. Suggested mechanism for cyclization of $\alpha, \omega$-bifunctional substrates 55 and 58 . 


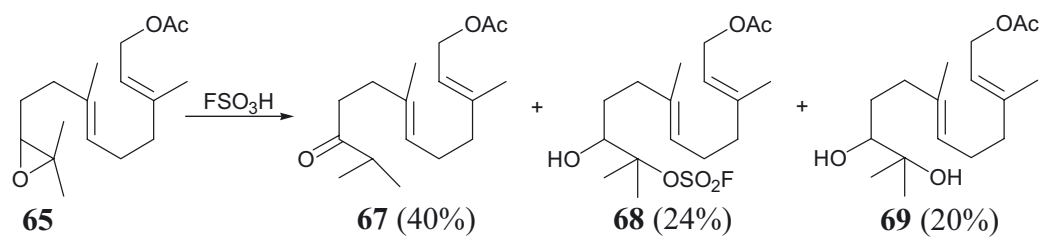

65

$67(40 \%)$

$68(24 \%)$

$69(20 \%)$

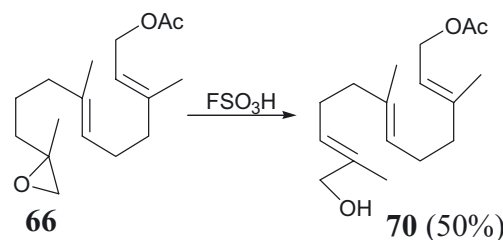

diterpenic compounds have additional internal double bonds that could be protonated for the initiation of the cyclization sequence. The probability of this process is higher, provided that the terminal double bond is not accessible due to the protection effect of the terminal functionalization. Potential products derived from this kind of cyclization would possess a cyclic system with a free prenyl group attached to the gem-dimethyl position of A-ring. These compounds have been found in natural sources but are hardly available and the described synthetic schemes (Hagiwara \& Uda, 1988; 1989; 1990; 1991) include a lot of steps which make them unattractive as preparative methods. At this point we shall mention that sesquiterpenic monocyclic compounds with an attached isoprene residue at the gem-dimethyl position of the cycle have been isolated in minor amounts from the cyclization products of corresponding open chain precursors, but their yield was very low (Armstrong et al., 1982; Polovinka et al., 1994).

Similarly to the strategy employed for monoterpenic substrates, the investigation of sesquiterpenic terminal epoxides cyclization was performed first. Accordingly, epoxyfarnesylacetates 65 and $\mathbf{6 6}$ were synthesized and treated with fluorosulfonic acid at low temperature (Ungur et al., 1993a; 1993b). The isolated reaction products $67-70$ proved to have a similar structure as in the case of monoterpenic epoxides 48 and 49 (Scheme 14). No products of carbocyclization were detected in the reaction product mixtures.

These results show clearly that terminal terpenic epoxides (mono- and sesquiterpenic) have the tendency to undergo only the opening of the epoxidic ring under superacidic treatment, without initiation of a cascade of cyclizations, eventually initiated from the internal double bond. It is very difficult to
Scheme 14. Interaction of sesquiterpenic terminal epoxides with fluorosulfonic acid.

find a reasonable theoretical explanation to these results, most probably such a reaction course is governed by both stereo-electronic factors and epoxide group reactivity.

Investigation of other functional groups attached to the $\omega$-terminus of the sesquiterpenic fragment has provided more interesting results (Kulcițki et al., 2000). The substrate of choice was the benzylic ether of $\omega$-hydroxyfarnesol 71 . The benzylic protection has been chosen following the analogy with the cyclizations of bifunctionalized monoterpenes discussed above. Besides its stability, the presence of the benzylic protection assures straightforward interpretation of cyclization process that was obviously seen in the case of monoterpenes.

The synthesis of compound $\mathbf{7 1}$ was performed by direct allylic oxidation of farnesylbenzyl ether promoted by selenium dioxide. Following treatment of this hydroxy-ether with fluorosulfonic acid at low temperature provided disappointing results. The reaction product represented a complex mixture of unidentifiable compounds. In contrast, superacidic treatment of the acetate 72 , obtained after $\mathrm{Ac}_{2} \mathrm{O} / \mathrm{Py}$ acetylation of 71 , provided a very good yield of a cyclic product, which proved to be a mixture of two epimeric compounds 73 and 74 (Scheme 15).

Formation of the ring A-prenylated compounds 73 and 74 was in line with the expectations of a specific inhibition function of the terminal acetoxy-functional group on the terminal double bond reactivity. The suggested reaction mechanism that explains formation of partially cyclized compounds is presented in Scheme 16. On treatment with a superacid, the $\omega$-acetoxy group of $\mathbf{7 2}$ is protonated to give the carbonium-ion 75 , which does not allow the protonation of the terminal double bond because this would lead to the formation of an energetically
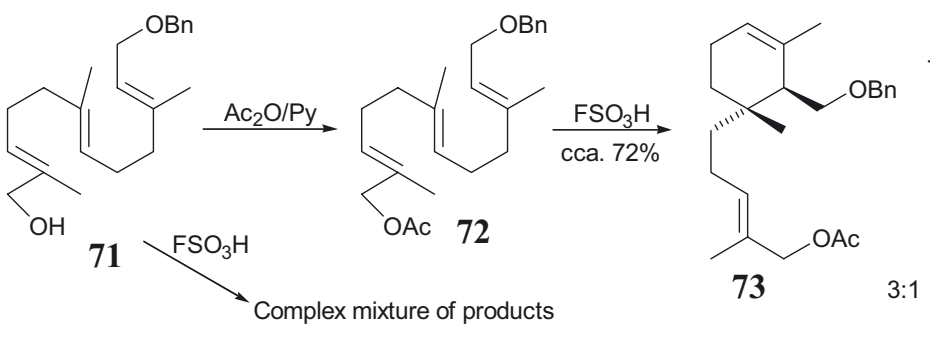

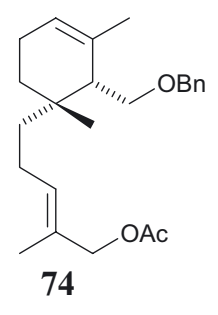

Scheme 15. Superacidic cyclization of $\alpha, \omega$-bifunctionalized sesquiterpenic substrates. 


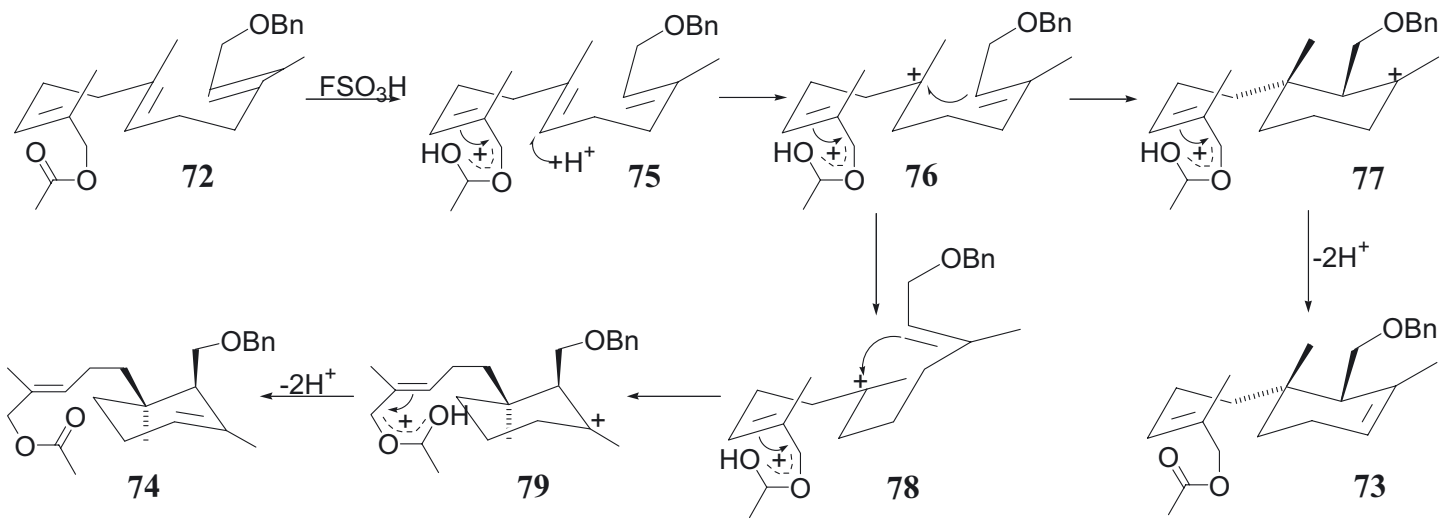

Scheme 16. Suggested mechanism of $\alpha, \omega$-bifunctional sesquiterpene 72 cyclization.

unfavourable 1,3-dicationic system, whereas the protonation of $\Delta^{6,7}$-double bond occurs with the formation of the dication 76, transformed into both dications 77 and 79.

Deprotonation of 77 and 79 leads to the final compounds 73 and 74, respectively. The dication 77 with two equatorial chains is more stable and consequently compound 73 predominates over its diastereomer 74. In such a way, the $\omega$-allylic acetoxy group in the sesquiterpenic substrate deactivates the terminal double bond. The cyclization process, starting from the internal double bond, gives rise to monocyclic terpenoids with prenylated gem-dimethyl groups in the ring. It should be mentioned that such cyclic compounds have been isolated from natural sources, the most prominent examples being compounds of seco-eudesmane structure which have been shown to have both cytotoxic and anti-bacterial activity (Asakawa, 1995; Perry \& Foster, 1995; Tori et al., 1996; Kumar et al., 2005).

Diterpenic compounds with functional groups at both $\alpha$ - and $\omega$-ends are not so often found in natural sources. To the best of our knowledge there is only one paper reporting isolation of the biologically active $\alpha, \omega$-bifunctionalized diterpenes 80-83 from the fungus Boletinus cavipes (Kamo et al., 2004). These compounds were shown to be inhibitors of superoxide anion generation in macrophage cells and are of interest in the prevention of oxidative-stress-related diseases.

We have recently performed the synthesis of the natural compound $\mathbf{8 0}$, as well as of some its derivatives 84-86, starting from the readily avail- able geraniol 3 (Scheme 17) and making use of the phenylsulfone coupling methodology (Grinco et al., $2007 b$ ). But our ultimate goal was the investigation of superacid-induced cyclization of these substrates, especially of acetates 85 and 86. Bearing in mind that the $\omega$-acetoxy group contributes to the initiation of the cyclization from internal double bonds it was expected that on cyclization of substrates 85 and 86 a diterpenic bicyclic compound would be formed, having the gem-dimethyl group of cycle A prenylated and belonging to the sacculatane family.

The work on superacidic cyclization of acetate 86 included an alternative procedure for its synthesis. The starting compound was the commercially available geranyllinalool 87 (Scheme 18). It was acetylated under standard conditions to geranyllinalyl acetate 88, which was isomerized with $\mathrm{PdCl}_{2}(\mathrm{MeCN})_{2}$ to a mixture (about 85:15) of 2E/2Z-geranylgeranyl acetates 89. This mixture was treated with NBS followed by potassium carbonate according to the Van Tamelen procedure to provide $\omega$-epoxy-trans-geranylgeraniol 90. Periodate cleavage of the epoxide 90 and protection of the free hydroxyl in 91 as THPether provided the substrate $\mathbf{9 2}$ for the Wittig olefination. This reaction proceeded in a good yield and selectivity: the E-isomer of the aldehyde 93 was isolated in a $68 \%$ yield. Sodium borohydride reduction of 93, followed by standard protecting group manipulations, afforded the desired $\alpha, \omega$-bifunctionalized substrate $\mathbf{8 6}$.

The structure of 86 was confirmed by spectral data. It should be mentioned that our attempts to perform a direct allylic oxidation of the terminal

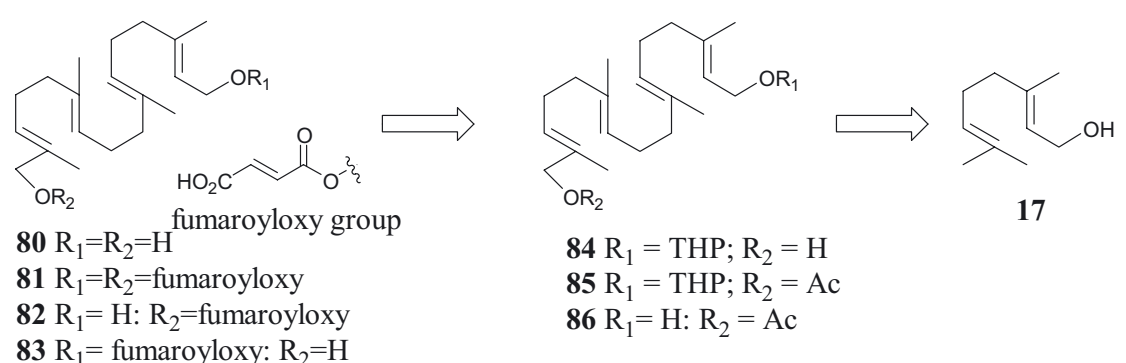

Scheme 17. Retrosynthetic scheme applied for the synthesis of $\alpha, \omega$-bifunctionalized open chain diterpenes. 


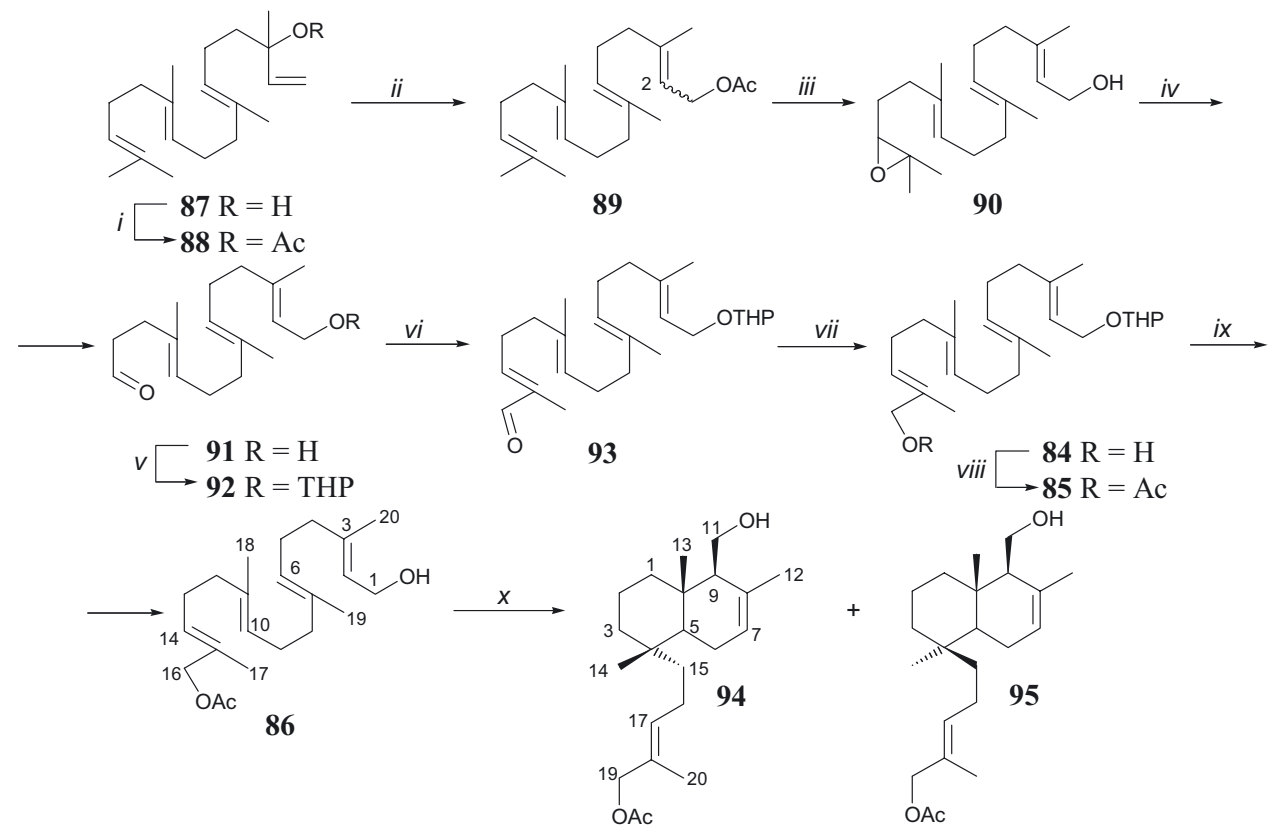

Scheme 18. Reagents and conditions.

(i) $\mathrm{Ac}_{2} \mathrm{O}, \mathrm{CH}_{2} \mathrm{Cl}_{2}$, 4-DMAP, $0^{\circ} \mathrm{C}, 1$ h, r.t. $24 \mathrm{~h}, 63 \%$; (ii) $\mathrm{PdCl}_{2}\left(\mathrm{MeCN}_{2}\right.$, THF, r.t, 18 h, 90\%; (iii) 1) NBS, THF-H $\mathrm{H}_{2} \mathrm{O}, 0^{\circ} \mathrm{C}$, 1.5 h, r.t. 2 h; 2) $\mathrm{K}_{2} \mathrm{CO}_{3}, \mathrm{MeOH}$, r.t. 20 h, overall 34\%; (iv) $\mathrm{NaIO}_{4}, \mathrm{HIO}_{4}$, THF, r.t. 5 h, (v) $\mathrm{DHP}, \mathrm{CH}_{2} \mathrm{Cl}_{2}, \mathrm{PPTS}, 12$ h, $46 \%$ after two steps; (vi) $\mathrm{Ph}_{3} \mathrm{P}=\mathrm{C}\left(\mathrm{CH}_{3}\right) \mathrm{CHO}$, THF, reflux, $18 \mathrm{~h}, 79 \%$; (vii) $\mathrm{NaBH}_{4}, \mathrm{EtOH}, 0^{\circ} \mathrm{C}, 1 \mathrm{~h}, 66 \%$; (viii) $\mathrm{Ac}_{2} \mathrm{O}, \mathrm{Py}$, r.t., 1 h, 96\%; (ix) p-TsOH, $\mathrm{MeOH}$, r.t. 12 h, 53\%; (x) $\mathrm{FSO}_{3} \mathrm{H}$ (5 equiv.), i- $\mathrm{PrNO}_{2},-78^{\circ} \mathrm{C}$, then $\mathrm{Et}_{3} \mathrm{~N}, 15 \mathrm{~min}, 25 \%$.

methyl group in compound 89 with $\mathrm{SeO}_{2}$ led to a complex mixture of products.

Superacidic cyclization of 86 was carried out by treatment with 5 equivalents of fluorosulfonic acid $\left(-78^{\circ} \mathrm{C}, 15 \mathrm{~min}\right)$ affording a mixture (about 3:1) of racemic compounds 94 and 95 (summary yield $25 \%$ ). The reaction mixture was purified by reversephase HPLC to give the corresponding individual compounds. Their structure was elucidated on the basis of spectral data.

The proposed reaction mechanism for cyclization of monoester 86 is shown in Scheme 19. On treatment with superacid, the $\omega$-acetoxy group of $\mathbf{8 6}$ is protonated to give the carboxonium ion 96, which does not allow the protonation of the terminal dou- ble bond, as it was mentioned above, whereas the protonation of $\Delta^{10,11}$-double bond occurs with the formation of the dications 97 or 98 , transformed into both dications 99 and 100. Further cyclization of 99 and 100 to 101 and 102 and deprotonation leads to the final compounds 94 and 95, respectively. The prevalence of isomer 94 in the reaction product mixture is explained by the fact that the open chain conformation 97 with the bulky group in quasi-equatorial position is energetically more favourable than the conformation 98 which leads to compound 95 having the bulky group in axial configuration.

The proposed reaction mechanism mimics the biosynthetic scheme that leads to sacculatane skeleton. Basing on biogenetical reasons, formation of

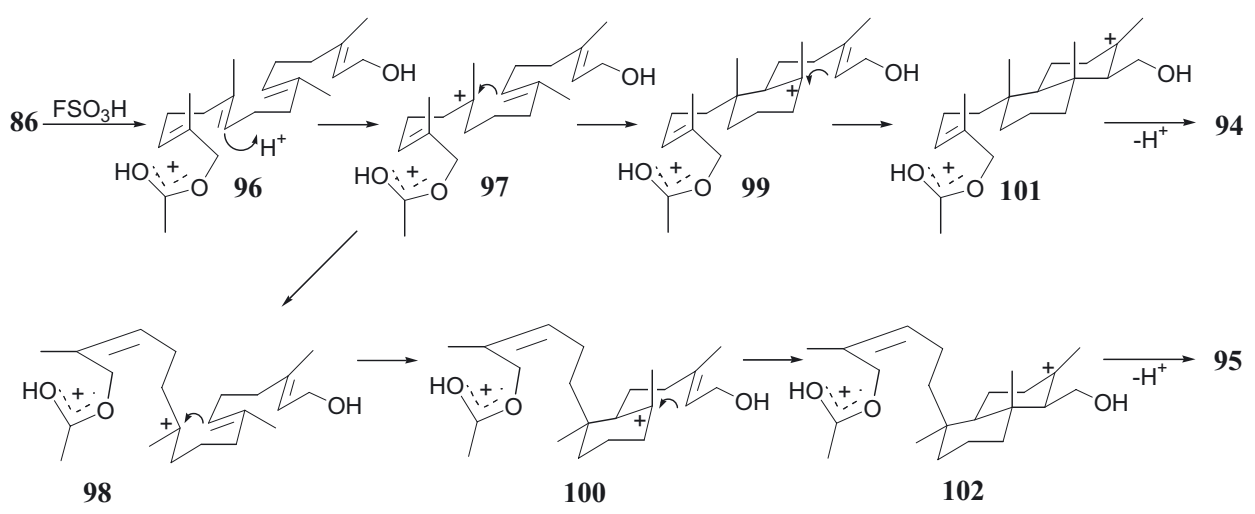

Scheme 19. Mechanism of cyclization of $\alpha, \omega$-bifunctional diterpene 86 . 


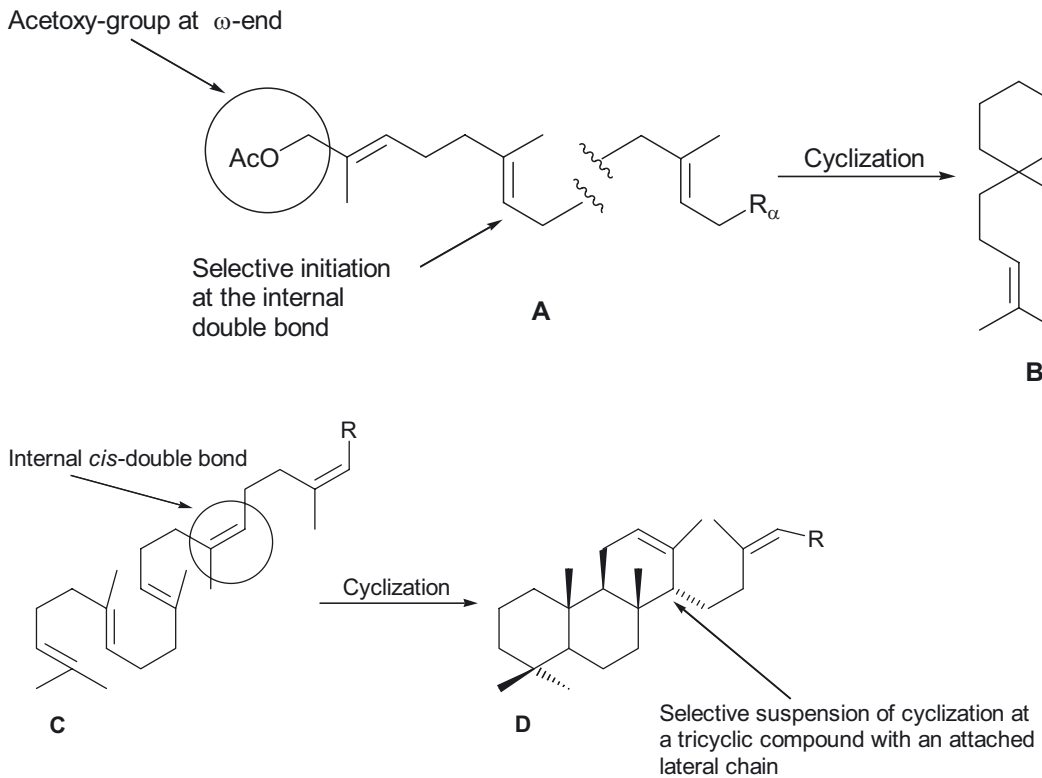

Scheme 20.

the prenylated bicyclic core of sacculatanes can only take place by a selective cyclization process of an open chain diterpenic precursor. The direct biosynthetic attachment of the C5 unit to a bicyclic core is unlikely to occur.

\section{CONCLUDING REMARKS}

The examples of terpene cyclizations presented in the current paper demonstrate that superacidic cyclization is a viable solution for the synthesis of complex cyclic terpenoids in a biomimetical manner. The most successful results reported for the monofunctional terpenic substrates show that the structure of the cyclic compounds does not depend strongly on the chain length of the corresponding precursor. As a rule, these products are completely cyclic having trans-fusion of rings. It appears that the chain length of the substrate influences most of all the reaction yields and selectivity. The best results have been obtained for sesqui- and diterpenic compounds. The lowering of the cyclization yield for higher substrates can be explained by additional conformational effects caused both by the increasing chain length of the substrate and the temperature conditions used for the superacid-promoted reactions.

The second important remark relates to the possibility of selective directing of the cyclization process by a careful selection of additional functional groups attached to the terpenic chain. It is possible to selectively initiate the cyclization process from an internal double bond for the synthesis of cyclic compounds of type $\mathbf{B}$, prenylated at gem-dimethyls of the obtained cycle (Scheme 20). The pre-requisite of this selectivity is a functional group (-OAc) introduced at the $\omega$-terminus of the terpene molecule $\mathbf{A}$. The best process selectivity has been obtained for the sesquiterpenic $\alpha, \omega$-bifunctionalized substrate.

On the other hand, inclusion in the chain of substrate $\mathbf{C}$ of an internal cis-double bond promotes a selective suspension of cyclization process to partially cyclic compounds D (Scheme 21). This selectivity was shown on the example of the cyclization of a polyprenol-like substrate in an attempt to provide a biogenetical correlation between polyprenols and other terpenic cyclic compounds isolated from natural sources.

Finally, it is necessary to mention that the field of acid-induced cyclization of terpenoids is still a challenge for organic synthetic chemists, especially from the point of view of access to highly functionalized cyclic targets. Further investigations are necessary in order to find more efficient promoters of cyclization sequence, promoters that work well in a wide temperature range, provide selectivity with substrates of different chain length and tolerate the diversity of functional groups present in the terpenic substrates.

\section{REFERENCES}

Armstrong RJ, Harris FL, Weiler L (1982) Electrophilic cyclization of polyene allylsilanes. Synthesis of albicanyl acetate. Can I Chem 60: 673-675.

Asakawa Y (1995) Chemical constituents of the bryophytes. In Progress in the Chemistry of Organic Natural Products. Herz W, Kirby WB, Moore RE, Steglich W, Tamm Ch, eds. 65: pp 1-618. Springer, Vienna.

Asakawa Y (2001) Recent advances in phytochemistry of bryophytes-acetogenins, terpenoids and bis(bibenzyl)s from selected Japanese, Taiwanese, New Zealand, Ar- 
gentinean and European liverworts. Phytochemistry 56: 297-312.

Asakawa Y (2004) Chemosystematics of the Hepaticae. Phytochemistry 65: 623-669.

Bartlett PA (1984) In Asymmetric Synthesis. Morrison JD, ed, 3: pp 341-409. Academic Press, New York.

Brunoldi E, Luparia M, Porta A, Zanoni G, Vidari G (2006) Biomimetic cyclizations of functionalized isoprenoid polyenes: cornucopia of synthetic opportunities. Curr Org Chem 10: 2259-2282.

De Carvalho MS, Jacobs RS (1991) Two-step inactivation of bee venom phospholipase A2 by scalaradial. Biochem Pharmacol 42: 1621-1627.

Cimino G, De Stefano S, Minale L (1974) Scalaradial, a third sesterterpene with the tetracarbocyclic skeleton of scalarin, from the sponge Cacospongia mollior. Experientia 30: 846-847.

Cimino G, Sodano G, Spinella A (1987) Correlation of the reactivity of 1,4-dialdehydes with methylamine in biomimetic conditions to their hot taste covalent binding to primary amines as a molecular mechanism in hot taste covalent receptors. Tetrahedron 43: 5401-5410.

Della Monica C, Della Sala G, Izzo I, De Petrocellis L, di Marzo V, Spinella A (2007) Enantioselective synthesis of 1-(R)-hydroxypolygodial and its $9 \alpha$ epimer, 1-(R)hydroxyisotadeonal. Tetrahedron 63: 6866-6873.

Feld H, Hertewich UM, Zapp J, Becker H (2005) Sacculatane diterpenoids from axenic cultures of the liverwort Fossombronia wondraczekii. Phytochemistry 66: 1094-1099.

Gavriliuk OA, Korchagina DV, Osadchii SA, Barkhash BA (1988) Cyclization of acyclic isoprenoids. IV. Ring closure with the formation of C2-oxygen atom bond. Zhurnal Org Khim (Journal of Organic Chemistry, Russian) 5: 966.

Grinco M, Kulcițki V, Ungur N, Jankowski W, Chojnacki T, Vlad PF (2007a) Superacid-catalyzed cyclization of methyl (6Z)-geranylfarnesoates. Helv Chim Acta 90: 1223-1229.

Grinco M, Kulcițki V, Ungur N, Barba A, Deleanu C, Vlad $P(2007 b)$ Synthesis of 16-hydroxygeranylgeraniol and its derivatives from geraniol. Khim Prirod Soed (Chemistry of Natural Compounds, Russian) 43: 277-281.

Grosjean E, Poinsot J, Charrié-Duhaut A, Tabuteau S, Adam P, Trendel J, Schaeffer P, Connan J, Dessort D, Albrecht P (2001) Synthesis and NMR characterization of novel highly cyclized polyprenoid hydrocarbons. J Chem Soc, Perkin Trans 1: 711-719.

Hagiwara H, Uda H (1988) Total synthesis of (+)-dysideapalaunic acid. J Chem Soc, Chem Commun: 815-817.

Hagiwara H, Uda H (1989) A total synthesis of (-)-sacculatal. Bull Chem Soc Jpn 62: 624-626.

Hagiwara H, Uda H (1990) Total synthesis of (+)-perrottetianal. J Chem Soc, Perkin Trans 1: 1901-1908.

Hagiwara H, Uda H (1991) Total synthesis and absolute stereostructure of (+)-dysideapalaunic acid. J Chem Soc, Perkin Trans 1: 1803-1807.

He H, Kulanthaivel P, Baker BJ (1994) New cytotoxic sesterterpenes from the marine sponge Spongia sp. Tetrahedron Lett 35: 7189-7192.

Jaki B, Heilmann J, Sticher O (2000) New antibacterial metabolites from the cyanobacterium Nostoc commune (EAWAG 122b). J Nat Prod 63: 1283-1285.

Jansen BJM, de Groot A (2004) Occurrence, biological activity and synthesis of drimane sesquiterpenoids. Nat Prod Rep 21: 449-477.

Jaquesy JC (1997) Natural product chemistry in superacids. In Stable carbocation chemistry. Prakash SGK, Schleyer PVR, eds, pp 549-574. John Wiley\&Sons, New York.
Kamo T, Sato K, Seri K, Shibata H, Hirota M (2004) Geranylgeraniol-type diterpenoids, Boletinins A-J, from $\mathrm{Bo}$ letinus cavipes as inhibitors of superoxide anion generation in macrophage cells. J Nat Prod 67: 958-963.

Kamaya R, Masuda K, Suzuki K, Ageta H, Hsu H-Y (1996) Fern constituents. Sesterterpenoids isolated from fronds of Aleuritopteris mexicana. Chem Pharm Bull 44: 690-694.

Kernan MR, Faulkner DJ, Parkanyi L, Clardy J, De Carvalho MS, Jacobs RS (1989) Luffolide, a novel anti-inflammatory terpene from the sponge Luffariella sp. Experientia 45: 388-390.

Korchagina DV, Gavriliuk OA, Barkhash VA, Vlad PF, Ungur N, Popa N (1993) Isomerisation of 6,7-epoxygeranylacetate in superacids. Zhurnal Org Khim (Journal of Organic Chemistry, Russian) 2: 323-325.

Kulcițki V, Ungur N, Vlad P (1998) Superacidic cyclization of terpenic phenylsulfones. Tetrahedron 54: 1192511934.

Kulcițki V, Ungur N, Deleanu C, Vlad PF (1999) Superacidic cyclization of $\omega$-oxygeraniol diacetate and benzyl ether of $\omega$-acetoxygeraniol. Russ Chem Bull 1: 135-137.

Kulcițki V, Ungur N, Vlad P, Gavagnin M, Castelluccio F, Cimino G (2000) Superacidic cyclization of all-trans- $\omega$ acetoxyfarnesyl benzyl ether. Synthesis 3: 407-410.

Kumar SK, Amador M, Hidalgo M, Bhatb SV, Khan SR (2005) Design, synthesis and biological evaluation of novel riccardiphenol analogs. Bioorg Med Chem 13: 2873-2880.

Kurbanov M, Semenovskii AV, Smit VA (1973) Cyclization of isoprenoid compounds. Communication 27. Fluorosulfonic acid - a new perspective cyclization agent. Izv Acad Nauk USSR, Ser Khim 2: 390 (in Russian).

Lan WJ, Li HJ (2007) New sesterterpenoids from the marine sponge Phyllospongia papyracea. Helv Chimica Acta 90: $1218-1222$.

Malheiros A, Cechinel Filho V, Schmitt CB, Yunes RA, Escalante A, Svetaz L, Zacchino S, Delle Monache F (2005) Antifungal activity of drimane sesquiterpenes from Drimys brasiliensis using bioassay-guided fractionation. I Pharm Pharmaceut Sci 8: 335-339.

Perry NB, Foster LM (1995) Sesquiterpenequinol from a New Zealand liverwort, Riccardia crassa. J Nat Prod 58: 1131-1135.

Polovinka MP, Korchagina DV, Gatilov YuV, Bagrianskaya IYu, Barkhash VA, Shcherbukhin VV, Zefirov NS, Perutsky VB, Ungur ND, Vlad PF (1994) Cyclization and rearrangements of farnesol and nerolidol stereoisomers in superacids. J Org Chem 59: 1509-1517.

Potts BCM, Faulkner DJ, De Carvalho MS, Jacobs RS (1992) Chemical mechanism of inactivation of bee venom phospholipase A2 by the marine natural products manoalide, luffariellolide, and scalaradial. J Am Chem Soc 114: 5093-5100.

Renoux J-M, Rohmer M (1986) Enzymatic cyclization of all-trans pentaprenyl and hexaprenyl methyl ethers by a cell-free system from the protozoon Tetrahymena pyriformis. The biosynthesis of scalarane and polycyclohexaprenyl derivatives. Eur J Biochem 155: 125-132.

Schaeffer P, Poinsot J, Hauke V, Adam P, Wehrung P, Trendel JM, Albrecht P, Dessort D, Connan J (1994) Novel optically active hydrocarbons in sediments: evidence for an extensive biological cyclization of higher regular polyprenols. Angew Chem, Int Ed 33: 1166-1169.

Sutherland JK (1991) Polyene cyclizations. In Comprehensive organic syntheses. Trost BM, Fleming I, eds, 3: pp 341-377. Pergamon Press, New York.

Swiezewska E, Sasak W, Mankowski T, Jankowski W, Vogtman T, Krajewska I, Hertel J, Skoczylas E, Cho- 
jnacki T (1994) The search for plant polyprenols. Acta Biochim Polon 41: 221-260.

Tori M, Hamaguchi T, Sagawa K, Sono M, Asakawa Y (1996) Total synthesis and absolute configuration of riccardiphenols $\mathrm{A}$ and $\mathrm{B}$, isolated from the liverwort Riccardia crassa. J Org Chem 61: 5362-5370.

Torre MC, Sierra MA (2004) Comments on recent achievements in biomimetic organic synthesis. Angew Chem, Int Ed 43: 160-181.

Ungur N, Kulcitki V (2007) Occurrence, biological activity and synthesis of cheilanthane sesterterpenoids. In preparation.

Ungur N, Popa N, Vlad PF (1993a) Interaction of 6,7-epoxygeranylacetate and 10,11-epoxyfarnesylacetate with fluorosulfonic acid. Khim Prirod Soed (Chemistry of Natural Compounds, Russian) 5: 691-697.

Ungur N, Popa N, Kulcițki V, Vlad PF (1993b) Interaction of terminal epoxides of $\alpha$-geranyl and $\alpha$-farnesylace- tate with fluorosulfonic acid. Khim Prirod Soed (Chemistry of Natural Compounds, Russian) 5: 697-701.

Ungur N, Kulcitki V, Gavagnin M, Castelluccio F, Vlad PF, Cimino G (2002) Studies towards the synthesis of cheilanthane sesterterpenoids: superacidic cyclisation of methyl 13Z, 17Z- and 13Z, 17E-bicyclogeranylfarnesoates. Tetrahedron 58: 10159-10165.

Van Tamelen EE (1968) Bioorganic chemistry: sterols and acyclic terpene terminal epoxides. Acc Chem Res 1: 111.

Van Tamelen EE, McCormic JP (1969) Terpene terminal epoxides. Mechanistic aspects of conversion to the bicyclic level. J Am Chem Soc 91: 1847-1848.

Van Tamelen EE, Storni A, Hessler EJ, Schwartz MA (1982) Cyclization studies with (+)-10,11-oxidofarnesyl acetate, methyl farnesate and (+)-10,11'-oxido-farnesate. Bioorg Chem 11: 133.

Vlad PF (1993) Superacidic cyclization of terpenoids. Pure Appl Chem 6: 1329-1336. 